\title{
O FRAGMENTO POÉTICO EM CADERNOS DE JOÃO, DE ANÍBAL MACHADO
}

\section{THE POETIC FRAGMENTS IN ANÍBAL MACHADO'S CADERNOS DE JOÃO}

\author{
Adalberto Luis VICENTE ${ }^{14}$
}

\begin{abstract}
RESUMO: Os Cadernos de João (1957) encerram três livros anteriores de Aníbal Machado: ABC das catástrofes, Topografia da insônia e Poemas em prosa. A originalidade da coletânea está no fato de que abriga uma diversidade de formas e gêneros, entre eles o fragmento e o poema em prosa. Neste trabalho, propomo-nos a estudar o fragmento poético nos Cadernos de João, a partir da ideia de poiesis, tal como a concebeu os primeiros românticos alemães, sobretudo Schlegel e Novalis, para o quais o fragmento era capaz de incorporar, a um só tempo, crítica, teoria e criação.
\end{abstract}

PALAVRAS-CHAVE: Poesia brasileira; Modernismo; Aníbal Machado; Fragmento; Poiesis.

ABSTRACT: Cadernos de João (1957) comprises three former books by Aníbal Machado: ABC das catástrofes [An ABC to Disasters], Topografia da insônia [Topography of Insomnia] and Poemas em prosa [Prose Poems]. The originality of that collection is due to the fact that it boasts a range of forms and genres, among which the fragment and the prose poem. This essay aims to study the poetic fragment in Cadernos de João starting from the idea of poiesis, as it was formulated by the earlier German Romantics, especially Schlegel and Novalis, for whom the fragment was able to embody criticism, theory and creation at the same time.

KEYWORDS: Brazilian poetry; Modernism; Aníbal Machado; Fragment; Poiesis.

Em artigo intitulado "A fragmentação do texto literário: um artifício de memória?", Maria Luiza Oliveira Andrade (2007, p.125-126) lembra que “o binômio fragmentação/fragmentário é uma discussão em torno da qual se concatenam diversos aspectos da teoria literária, a exemplo da desrealização, da dissociação ser/mundo e da

\footnotetext{
${ }^{14}$ Departamento de Letras Modernas. Programa de Pós-Graduação em Estudos Literários - Faculdade de Ciências e Letras - Universidade Estadual Paulista (UNESP), campus de Araraquara - CEP 14800-901 Araraquara - SP - Brasil - E-mail: dal@ @clar.unesp.br
} 
decomposição do indivíduo." A não-linearidade discursiva ou lógica, as rupturas sintáticas, o "esfacelamento de perspectivas", as digressões pela memória, a mistura de gêneros e a intertextualidade são alguns dos sintomas textuais do fragmentário presentes na literatura moderna e pós-moderna. No final do século XVIII e início do XIX, cresce a consciência da dissociação ser/mundo e o binômio fragmentação/fragmentário se estabelece numa relação tensa com o ideal de totalidade a que aspirava o Romantismo, a ponto de os primeiros românticos alemães conceberem o fragmento como uma totalidade em devir. Posicionando-se contra as imposições limitadoras e normativas das estéticas clássicas, para as quais os modelos e os gêneros não podiam ser transgredidos, autores como Schlegel e Novalis propõem-se a buscar uma nova forma de expressão a partir da ideia de poiesis, ou seja, de linguagem criadora, que pudesse incorporar simultaneamente crítica, criação e teoria. Segundo Márcio Scheel (2009, p.10), Novalis e Schlegel

[...] foram os primeiros a conceber o ideal de que era possível a aproximação de realidades discursivas distintas, como as teórica, filosófica e poética, buscando novas formas de expressão do pensamento. [...] Comunicar o impulso poético a cada idéia, pensamento ou palavra, era esse o principal interesse de Novalis e Schlegel.

Uma passagem de $O$ dialeto dos fragmentos de Schlegel (1997, p.100-101) ilustra bem a intenção de romper com o isolamento entre filosofia, arte e ciência, questionando, assim, a imposição de uma visão estanque entre essas disciplinas:

Pensamentos entremesclados deveriam ser os esboços da filosofia. Sabe-se quanto estes valem para os que conhecem pintura. Para aquele que não puder rascunhar mundos filosóficos a lápis, não puder caracterizar com alguns rabiscos todo e qualquer pensamento que tenha filosofia, a filosofia jamais se tornará arte e, portanto, tampouco ciência. Pois na filosofia o único caminho que leva à ciência passa pela arte, assim como, ao contrário, só por meio da ciência o poeta se torna artista.

A série de termos "esboços", "rascunhar", "rabiscos" remete ao processo fragmentário da escritura. No entanto, é curioso como esses termos vêm acompanhados de expressões que remetem a uma totalidade: esboços "da filosofia", rascunhar 
"mundos filosóficos", rabiscos "de todo e qualquer pensamento". O fragmento encarnaria assim, em forma inacabada, a expressão total. Uma das consequências dessa concepção totalizante, que preconiza a fusão do juízo crítico e do espírito criador, manifesta-se na célebre proposta de Schlegel (1977, p.34) de esfumar os limites entre o discurso crítico e o poético quando se tratar de avaliar a poesia:

Poesia só pode ser julgada por poesia. Um juízo crítico que não é ele mesmo uma obra de arte na matéria, como exposição da impressão necessária em seu devir, ou mediante uma bela forma e um tom liberal no espírito da antiga sátira romana, não tem absolutamente direito de cidadania no reino da arte.

Desse modo, Schlegel busca resgatar a indistinção entre arte e pensamento, gosto e razão, que o espírito racional e crítico instaurado a partir do século XVII havia separado de modo irreconciliável. Essa separação se dá também no nível retórico. Cada campo do conhecimento estabelece suas fronteiras discursivas, seus jargões específicos. A filosofia e a ciência constituem, a partir de então, um "esforço de investigação do pensamento que não deve ser penalizado pela beleza do estilo" (SUZUKI, 1998, p.53). Nesse contexto, o fragmento apresenta-se como uma forma capaz de romper fronteiras discursivas e disciplinares, de amalgamar gêneros e formas, atitude que está na origem do processo de hibridação pelo qual passará a literatura a partir do Romantismo. Em sua busca de totalidade, o gênio romântico não reconhece mais barreiras entre as faculdades de pensar e imaginar, como lembra Márcio Suzuki (1998, p.58):

[...] o gênio é, a seu modo, o preenchimento do vão que existe entre conceitos da razão e representações imaginárias: mediação ou condição da síntese entre essas duas faculdades e instituição de uma linguagem para exprimir as Idéias supra-sensíveis.

Neste sentido, o fragmento não se confunde com outras formas breves que lhe são próximas, o aforismo e o apotegma. O primeiro foi definido pelo próprio Schlegel como a maior quantidade de pensamento no menor espaço e por Nietzsche como a ambição de dizer em dez frases o que outro qualquer diz num livro. Já o apotegma é o pensamento de homens ilustres, registrado em sentenças, cujo exemplo mais conhecido é Apophthegmata Laconica de Plutarco. Contrariamente ao fragmento romântico, essas 
formas se destacam, sobretudo, pelo brilho do pensamento e não pretendem ser apreendidas também como objeto artístico.

O fragmento, tal como o conceberam os primeiros românticos alemães, parece ser um instrumento de análise bastante produtivo para se adentrar criticamente certos textos curtos presentes em Cadernos de João, de Aníbal Machado, uma das obras mais originais da poesia brasileira, tanto pela sua forma, quanto pelo seu lirismo. A coletânea é formada pela reunião de diversas formas fragmentárias: o fragmento propriamente dito, os poemas caleidoscópicos (vários fragmentos reunidos sob um título, cada um deles reverberando um aspecto do tema, cujo exemplo mais brilhante é o poema “Topografia da insônia”), o poema em prosa, o poema dramático, o poema de circunstância, cômico ou paródico etc.

O caráter fragmentário da coletânea é explicitado pelo próprio autor que, em nota inicial, datada de 20 de janeiro de 1957, afirma que o livro encerra, revistos e aumentados, o ABC das catástrofes e Topografia da insônia, de 1951, edição de vinte exemplares, e Poemas em prosa, de 1955, edição de 330 exemplares, sendo que os Poemas não obedecem à ordem primitiva (MACHADO, 2004, p.5). Mario Pontes, em ensaio de apresentação aos Cadernos de João, afirma que, para entrarem no novo livro, as obras anteriores "foram revistas e ampliadas, o que significou, ainda, a inclusão de um certo número de fragmentos inéditos no volume” (PONTES apud MACHADO, 2004, p.15). Assim, o volume estabelece uma tensão entre a dispersão de coletâneas anteriores e a busca de uma unidade sutil. Como os Pequenos poemas em prosa de Baudelaire, trata-se de um livro "sem cabeça nem cauda" (BAUDELAIRE, 1958, p.3), como os pedaços da serpente, cuja vantagem é que o leitor pode interromper e recomeçar a leitura onde quiser. A reunião de textos autônomos em uma coletânea, como percebeu Baudelaire, gera a possibilidade de que a leitura também se faça de modo fragmentário. Sua unidade está dispersa nas infinitas possibilidades associativas dos fragmentos.

A diversidade de formas e o aspecto fragmentário do livro de Aníbal Machado é consequência do processo de criação utilizado nos Cadernos, que pretendem ser um mapeamento do "descontínuo interior", como aponta o autor no poema liminar do livro, cujo título é "Caderno" (MACHADO, 2004, p.16): 
Mapa irregular do nosso descontínuo interior, com fragmentos, vozes, reflexões, imagens de lirismo e revolta - inclusive amostras de cerâmica verbal - dos muitos personagens imprecisos que os animam. Afloramento de íntimos arquipélagos, luzir espaçado das constelações predominantes...

$\mathrm{O}$ autor apenas se reserva o direito de administrar o seu próprio caos e de impor-lhe certa ordem na tranqüilidade formal das palavras.

Como se pode notar, o autor indica a origem e a proposta estética do livro: de seu próprio caos, do "descontínuo interior" brotam os fragmentos, vozes, reflexões, imagens de lirismo, aos quais será dada certa ordem ao se fixarem em palavras. A imagem da "cerâmica verbal" torna-se assim central nessa passagem. A cerâmica é, antes de seu cozimento, um material moldável e maleável, destinado a fixar-se em uma forma dura e perene. Assim é o processo criador proposto por Machado nos Cadernos de João. Fixação do transitório e do caos interior por meio da palavra que aflora no instante. Os fragmentos são capazes de dar conta dessa necessidade de expressão interior que funde reflexões, sensações, impulsos poéticos e vozes interiores.

Como acontece com os autores que escolhem a literatura para expressar suas ideias, a filosofia de Aníbal Machado é errante, dispersiva, alinhada com o pensamento de filósofos cujo discurso não se adequa à racionalidade do pensamento cartesiano, como é o caso de Rousseau, Nietzsche e Gabriel Marcel. O pensamento filosófico apresenta-se, nos Cadernos de João, de modo prático e concreto, fixado em filosofemas, realçado por imagens poéticas, sem constituir um sistema fechado e elaborado de modo racional. Neste estudo, deter-nos-emos em alguns fragmentos em que a influência do pensamento de Heráclito de Éfeso se faz presente.

O título do ensaio de Mário Pontes (PONTES apud MACHADO, 2004, p.7-13) que introduz os Cadernos de João refere-se a Aníbal Machado como o "iniciado do movimento". A expressão alude ao registro do transitório, à fascinação que o movimento exercia sobre o poeta. Segundo o crítico "o movimento estava no centro da visão de mundo de Aníbal Machado” (p.11). Para Heráclito de Éfeso (c. 540-470 a.C.), cujo pensamento chegou até nós de forma fragmentária, sobretudo por meio de seus comentadores, tudo o que existe está em movimento. Platão (1991, p.49), no Crátilo, sintetiza do modo seguinte a ideia heraclitiana de "panta rei", ou seja, "tudo flui", "tudo se move": 
Heráclito diz em alguma passagem que todas as coisas se movem e nada permanece imóvel. E, ao comparar os seres com a corrente de um rio, afirma que não poderia entrar duas vezes num mesmo rio [...] Heráclito retira do universo a tranquilidade e a estabilidade, pois isso é próprio dos mortos; e atribuía movimento a todos os seres, eterno aos eternos, perecível aos perecíveis.

Mário Pontes alude ao fato de que Heráclito é explicitamente citado em um dos poemas dos Cadernos. Trata-se de um texto bastante significativo para compreender a apropriação que Aníbal Machado (2004, p.23) faz do pensamento de Heráclito sobre a instabilidade dos seres:

$[\ldots]$

O sentimento dramático do movimento, do provisório, do vir a ser, deixa-nos a princípio num estado de flutuação e perigo, tontos em busca de direções, mas já num confuso pressentimento de pólos atrativos. E somos depois atirados dentro mesmo das forças vivas com as quais formamos, à nossa maneira, um Universo alimentado por energias humanas e telúricas em constante transformação e metamorfose.

Ó Heráclito, tua lição continua. Almas desamparadas, viúvas do Absoluto, podem a cada instante contrair novas núpcias.

Para Heráclito, filósofo da natureza, o fogo era o elemento originário de todas as coisas, sua transformação, condensação ou evaporação dava origem à transformação e movimento de todos os seres. Havia, portanto, na natureza, o "um", elemento que dava unidade a tudo, eterno em sua inconstância, que sempre tendia a decompor-se e recompor-se, convergindo para os contrários: “o contrário é convergente e dos divergentes nasce a mais bela harmonia, e tudo segundo a discórdia” (HERÁCLITO, 1991, p.52), afirma o filósofo em um de seus fragmentos. Aníbal Machado, na passagem acima, alude ao "sentimento dramático" que a consciência da transitoriedade provoca no poeta, que não mais crê na unidade de todas as coisas e desconfia de toda explicação metafísica, tornando-se assim o "viúvo do Absoluto". Abandonado na esfera do transitório, em sua "constante transformação e metamorfose", resta ao poeta "contrair núpcias" com sua própria condição de ser transitório e instável e tornar-se aquele que sempre está a caminho de "Santa Maria, castelo de passarinhos", como 
afirma o autor em um dos mais belos poemas da coletânea, "O transitório definitivo" (MACHADO, 2004, p.43):

\section{[...]}

Prendo-me aos seres e objetos com o fervor de quem vai perdêlos para sempre. Porque afinal este mundo, tal como está, se eu gosto dele um bocadinho, é no momento mesmo em que penso largá-lo. Mas isso eu nunca digo.

E vou andando...

Se alguém pergunta quem sou, respondem todos: Não se sabe. Vive dizendo que está indo para um castelo de passarinho...

Sempre assim.

Quando a vida me aborrece, largo tudo de repente, apanho a trouxa, e vou tocando devagarinho para Santa Maria, castelo de passarinhos...

O tema do desapego em relação aos seres e lugares, o fascínio pelo deslocamento no espaço, pela partida, pela viagem e pelos meios de locomoção que a propiciam, a busca incessante de algo que está além do horizonte e que o poeta sabe que não alcançará compõem o universo poético de diversos fragmentos. Em "O Viajante sem passaporte", por exemplo, o encanto da partida está no adiamento da chegada e a expectativa do encontro, que o poeta sabe impossível, eterniza-se no deslocamento, na chegada sempre preterida:

Enfim, o que importa é o frêmito da partida; a pista, a praia e a plataforma se afastando... a palpitação das águas no sulco distante da popa...

O que importa é a esperança vaga do encontro (que encontro?) alimentada pelo perpétuo adiamento da chegada.

Na poesia de Aníbal, o deslocar-se torna-se mais importante do que o ponto de partida ou de chegada. No tempo percorrido entre um espaço e outro se faz eterno o instante, mas este nunca encontra sua fixidez, pois no universo em que tudo flui não existe nada que possa ser considerado estável. O poeta emprega com certa frequência as palavras "frêmito" e "fremente" para designar a instabilidade do instante. Assim, o "frêmito da viagem" do poema acima é análogo ao "passeio fremente" da flecha em direção ao alvo, presente em outro fragmento: 
O melhor momento da flecha não é o da sua inserção no alvo, mas a da trajetória entre o arco e a chegada - passeio fremente (2004, p.49).

Se a pretensão do poeta é perenizar o transitório, interessa-lhe mais a trajetória da flecha do que o alvo a ser atingido.

Para Heráclito, há apenas duas coisas estáveis, o fogo, princípio de tudo, e uma propriedade imanente a esse elemento, o movimento. $\mathrm{O}$ que vemos no mundo e em nosso próprio ser são manifestações desse devir incessante, inesgotável, infinito, sem começo nem fim. O filósofo intuía assim o princípio da conservação do movimento que a física newtoniana iria revelar e formalizar matematicamente. A única coisa inquestionável que se pode afirmar ao se observar o mundo, é que tudo flui, tudo está em movimento. O primeiro fragmento dos Cadernos de João, intitulado "Descosendo o espaço", anuncia esse princípio heraclitiano por meio de imagens poéticas de um lirismo intenso:

O pássaro agonizante põe pela boca os milhares de quilômetros que devorou pelos ares (2004, p.19).

O texto faz alusão a dois elementos cuja natureza está associada ao movimento: o pássaro e os ares. Mario Pontes (2004) chama a atenção para o fato de que a poesia de Aníbal Machado, com frequência, põe diante do leitor seres em que o dinamismo faz parte de sua própria natureza, como o mar, o vento, o pássaro, o trem e o navio. A metáfora criada pelo emprego do verbo "devorar" sugere, neste caso, a fixação do movimento. O pássaro incorpora ao seu ser o espaço percorrido pelos ares, conservando-o durante a vida e devolvendo-o à natureza em seu último suspiro. Do ponto de vista fônico, as vogais da palavra pássaro irradiam-se pelo texto. Assim como o pássaro recolhe em si o espaço que percorreu, a palavra pássaro concentra na materialidade do signo o principal processo aliterativo do texto. Como pensava Heráclito, o movimento não se perde, mas é a única realidade que permanece para além da transitoriedade da existência.

O texto em questão é exemplar do modo como Aníbal Machado trabalha muitos dos fragmentos dos Cadernos de João. Uma certa visão de mundo é expressa por meio de uma elaboração poética altamente refinada em sua brevidade. Assim, o fragmento se 
apresenta, como queriam os primeiros românticos alemães, como uma síntese entre pensamento e poesia.

Aníbal Machado, o "iniciado do vento, do mar, do movimento", como o definiu Mario Pontes (2004, p.13), atribui ao poeta a missão de deter-se na transitoriedade, de "olhar bem para as coisas que de repente deixaremos de ver para sempre" ("O Verbo no infinito": MACHADO, 2004, p.20). O poeta torna-se assim aquele que, por meio de sua arte, torna-se "recuperador da presença perdida" e, mesmo vivendo entre os "destroços do palácio imaginário" (2004, p.33), retira sua força do poder de transformar em cerâmica verbal a consciência do provisório.

\section{REFERÊNCIAS}

ANDRADE, M. L. O. A fragmentação do texto literário: um artifício de memória? Interdisciplinas, v.4, n.4, jul/dez 2007. Acesso em 30/07/2010. Disponível em http://www.posgrap.ufs.br/periodicos/interdisciplinar/revistas/ARQ_INTER_4/INTER4 _Pg_122_131.pdf.

BAUDELAIRE, C. Petits poèmes en prose (Le Spleen de Paris). Introduction, notes, bibliographie et choix de variantes par Henri Lemâitre. Paris: Garnier, 1958.

MACHADO, A. Cadernos de João. Rio de Janeiro: J. Olympio, 2004.

PONTES, M. O iniciado do movimento. In: MACHADO, A. Cadernos de João. Rio de Janeiro: J. Olympio, 2004. p.7-13.

SCHEEL, M. A Literatura aos pedaços: a fragmentação discursiva e a problemática da representação do primeiro romantismo alemão à modernidade e ao pós-modernismo. 2009. Tese (Doutorado) - Faculdade de Ciências e Letras, Universidade Estadual Paulista, Araraquara, 2009.

SCHLEGEL, F. O dialeto dos fragmentos. Tradução, apresentação e notas de Marcio Suzuki. São Paulo: Iluminuras, 1997.

SOUZA, J. C. de (Seleção de textos e supervisão). Os Pré-Socráticos: fragmentos, doxologia e comentários. São Paulo: Abril Cultural, 1991 (Os Pensadores).

SUZUKI, M. O gênio romântico. Crítica e história da Filosofia em Friedrich Schlegel. São Paulo: Iluminuras/FAPESP, 1998. 